\title{
Solar pond technology
}

\author{
J SRINIVASAN \\ Department of Mechanical Engineering, Indian Institute of Science, \\ Bangalore 560012, India
}

MS received 10 April 1991; revised 15 February 1992

\begin{abstract}
Solar pond technology has made substantial progress in the last fifteen years. This paper reviews the basic principles of solar ponds and the problems encountered in their operation and maintenance. The factors which influence the technical and economic viability of solar ponds for thermal applications and power generation have been discussed.
\end{abstract}

Keywords. Solar ponds; renewable energy; solar energy.

\section{Introduction}

Solar energy is an abundant and renewable energy source. The annual solar energy incident at the ground in India is about 20,000 times the current electrical energy consumption. The use of solar energy in India has been very limited. This is because solar energy is a dilute energy source (average daily solar energy incident in India is $5 \mathrm{kWh} / \mathrm{m}^{2}$ day) and hence energy must be collected over large areas resulting in high initial capital investment; it is also an intermittent energy source. Hence solar energy systems must incorporate storage in order to take care of energy needs during nights and on cloudy days. This results in further increase in the capital cost of such systems. One way to overcome these problems is to use a large body of water for the collection and storage of solar energy. This concept is called a solar pond.

\section{Principle of a solar pond}

In a clear natural pond about $30 \%$ solar radiation reaches a depth of 2 metres. This solar radiation is absorbed at the bottom of the pond. The hotter water at the bottom becomes lighter and hence rises to the surface. Here it loses heat to the ambient air and, hence, a natural pond does not attain temperatures much above the ambient. If some mechanism can be devised to prevent the mixing between the upper and lower layers of a pond, then the temperatures of the lower layers will be higher than of the upper layers. This can be achieved in several ways. The simplest method is to make the lower layer denser than the upper layer by adding salt in the lower layers. The salt used is generally sodium chloride or magnesium chloride because of their low cost. Ponds using salts to stabilize the lower layers are called 'salinity gradient 

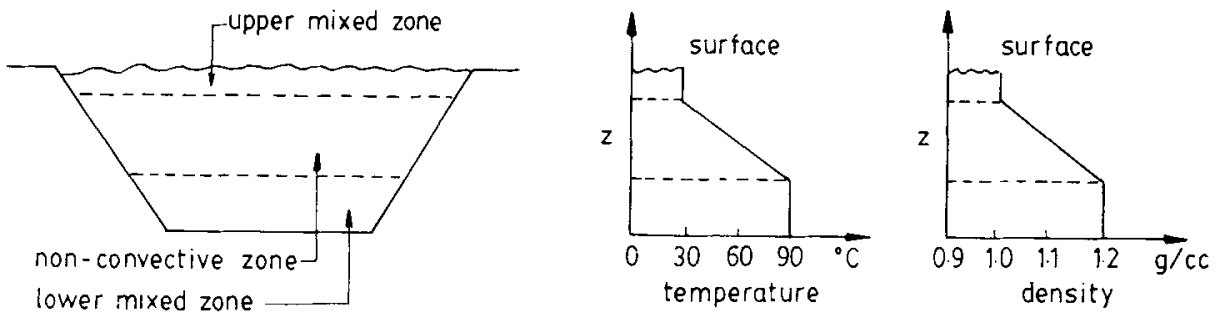

Figure 1. Different zones in a solar pond.

ponds'. There are other ways to prevent mixing between the upper and lower layers. One of them is the use of a transparent honeycomb structure which traps stagnant air and hence provides good transparency to solar radiation while cutting down heat loss from the pond. The honeycomb structure is made of transparent plastic material. Ortabasi \& Dyksterhuis (1985) have discussed in detail the performance of a honeycomb-stabilized pond. One can also use a transparent polymer gel as a means of allowing solar radiation to enter the pond but cutting down the losses from the pond to the ambient. Wilkins \& Lee (1987) have discussed the performance of a gel (cross-linked polyacrylamide) pond.

In this review we discuss salinity gradient solar ponds as this technology has made tremendous progress in the last fifteen years. Typical temperature and density profiles in a large salinity gradient solar pond are shown in figure 1. We find that there are three distinct zones in a solar pond. The lower mixed zone has the highest temperature and density and is the region where solar radiation is absorbed and stored. The upper mixed zone has the lowest temperature and density. This zone is mixed by surface winds, evaporation and nocturnal cooling. The intermediate zone is called the nonconvective zone (or the gradient zone) because no convection occurs here. Temperature and density decrease from the bottom to the top in this layer, and it acts as a transparent insulator. It permits solar radiation to pass through but reduces the heat loss from the hot lower convective zone to the cold upper convective zone. Heat transfer through this zone is by conduction only. The thicknesses of the upper mixed layer, the non-convective layer and the lower mixed layer are usually around 0.5 , $1 \mathrm{~m}$ and $1 \mathrm{~m}$, respectively.

\section{Thermal performance}

The thermal performance of a solar pond can be represented in a form similar to that used for conventional flat plate collectors. Assuming a steady state condition,

$$
Q_{u}=Q_{a}-Q_{e}
$$

where $Q_{u}=$ useful heat extracted, $Q_{a}=$ solar energy absorbed, $Q_{e}=$ heat losses.

The thermal efficiency of a solar pond can be defined as $\eta=\left(Q_{u} / I\right)$ where $I$ is the solar energy incident on the pond. Thermal efficiency can be written as $\eta=\eta_{0}-Q_{e} / I$, where $\eta_{0}$ is called the optical efficiency of the pond $\left(Q_{a} / I\right)$. We express $Q_{e}=U_{0}\left(T_{s}-T_{a}\right)$, where $T_{s}$ is the pond storage-zone temperature, $T_{a}$ is the ambient temperature and $U_{0}$ is the overall heat-loss coefficient. If we neglect heat losses from the bottom and sides of the pond and assume that the temperature of the upper mixed layer is the 


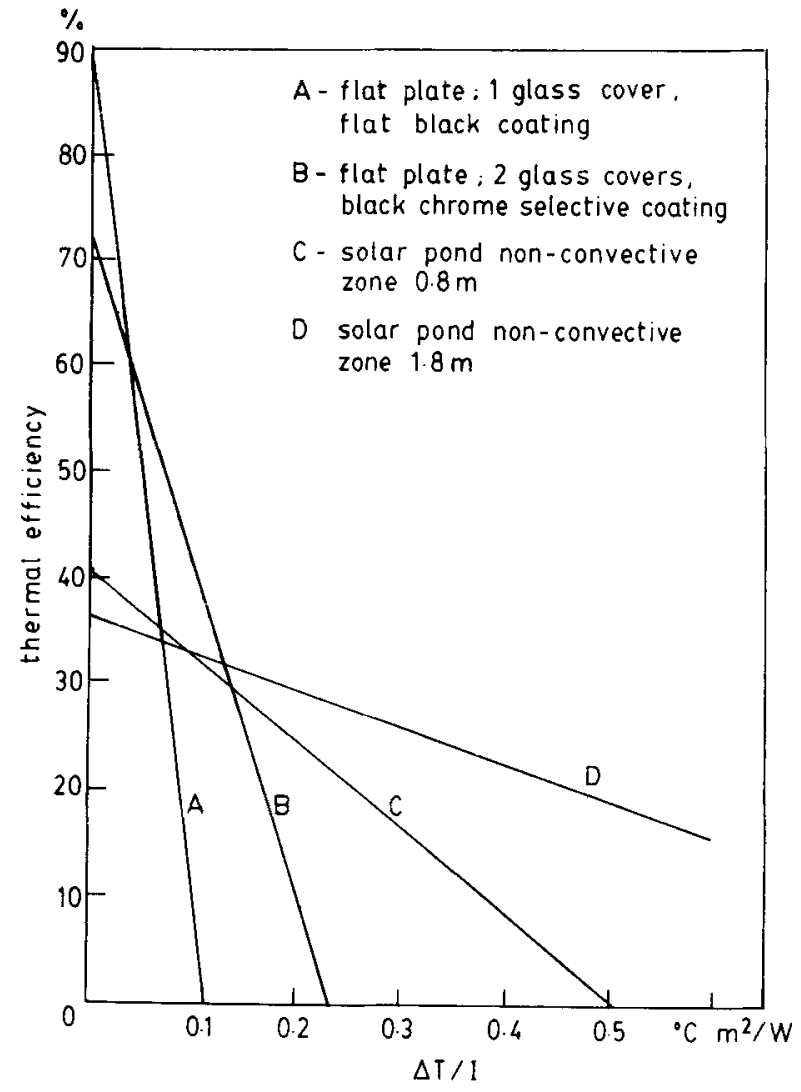

Figure 2. Variation of thermal efficiency with $\Delta T / I$, where $\Delta T$ is the temperature difference between the storage zone (or absorber) and the ambient, and $I$ is the intensity of solar irradiation.

same as the ambient, then $U_{0}=K_{w} / b$ where $K_{w}$ is the thermal conductivity of water and $b$ is the thickness of the gradient zone.

Kooi (1979) has compared the efficiency of a solar pond with those of conventional flat plate collectors as shown in figure 2 . We find that the thermal efficiency of a solar pond is higher than that of a flat plate collector when the operating temperatures are higher, and is in the range of 20 to $30 \%$ when the temperature difference is around $60^{\circ} \mathrm{C}$. The thermal efficiency is strongly dependent upon the transparency of the pond which is influenced by the presence of algae and dust. Even if the solar pond is free of dust and algae, the absorption properties of pure water influence the transmission of solar radiation in the pond. The transmissivity of solar radiation in pure distilled water is shown in figure 3. We observe that about half the solar radiation is absorbed in the first $50 \mathrm{~cm}$ of water. This is on account of strong infrared absorption bands in water. At a depth of 2 metres the transmission is about $40 \%$. This sets the upper limit on the thermal efficiency of a solar pond. The thickness of the gradient zone must be chosen depending on the temperature at which thermal energy is needed. If the thickness of the gradient zone is too high the transmission of solar radiation is reduced while if it is too small it causes high heat losses from the bottom to the top of the pond. The optimum value of the thickness depends on the temperature of the storage zone of the pond. Nielsen (1980) has provided a steady state analysis of a solar pond and has included the effect of solar radiation absorption in the gradient zone on the temperature profile. In the steady state, the energy equation becomes

$$
K\left(\mathrm{~d}^{2} T / \mathrm{d} Z^{2}\right)=I(\mathrm{~d} \tau / \mathrm{d} Z),
$$




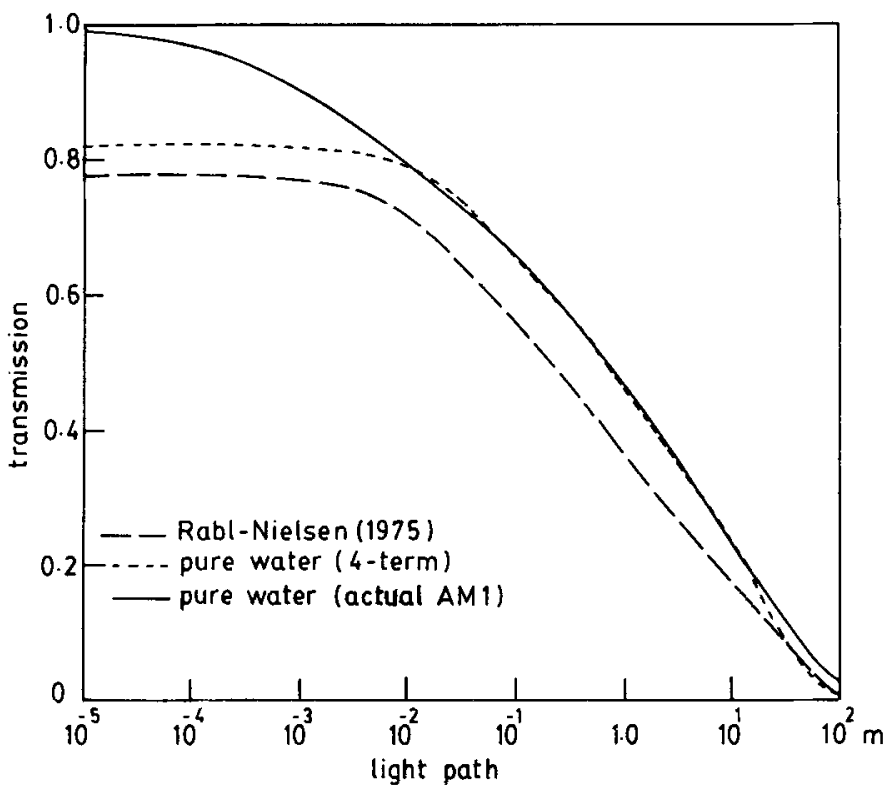

Figure 3. Variation of transmission of solar radiation with path length.

where $K$ is the thermal conductivity of water and $\tau$ is the fraction of solar radiation $I$ reaching a depth $Z$.

This equation can be integrated to get

$$
(\mathrm{d} T / \mathrm{d} Z)=\{I / K\}\left\{\tau(Z)-\tau\left(Z_{1}\right)+(\mathrm{d} T / \mathrm{d} Z)_{Z_{2}}\right\},
$$

where $Z_{2}$ is the interface between the gradient zone and storage zone. If $\eta$ is the fraction of the incident solar energy which is extracted from the system as heat (including ground losses), then an energy balance of the storage zone gives

$$
\left.(\mathrm{d} T / \mathrm{d} Z)\right|_{Z_{2}}=\{I / K\}\left\{\tau\left(Z_{2}\right)-\eta\right\} .
$$

We can combine (2) and (3) to obtain the temperature profile in the gradient zone as

$$
(\mathrm{d} T / \mathrm{d} Z)=\{I / K\}\{(\tau(Z)-\eta)\}
$$

The temperature profile in the gradient zone for various values of $\eta$ is shown in figure 4 for $I=200 \mathrm{~W} / \mathrm{m}^{2}$. Since $T$ is proportional to $I$, the above figure can also be used for other values of $I$ by multiplying by an appropriate constant.

The effect of ground-heat losses on the performance of a solar pond has been analysed by Hull et al (1984). They have shown that the ground heat-loss coefficient can be expressed as

$$
U_{g}=K(1 / D+b P / A)
$$

where $K$ is the ground conductivity. $D$ is the depth of the water table, $P$ and $A$ are the pond perimeter and surface area and $b$ is a constant whose value is around 0.9 (depending upon the side slope). The thermal efficiency of a steady state solar pond 


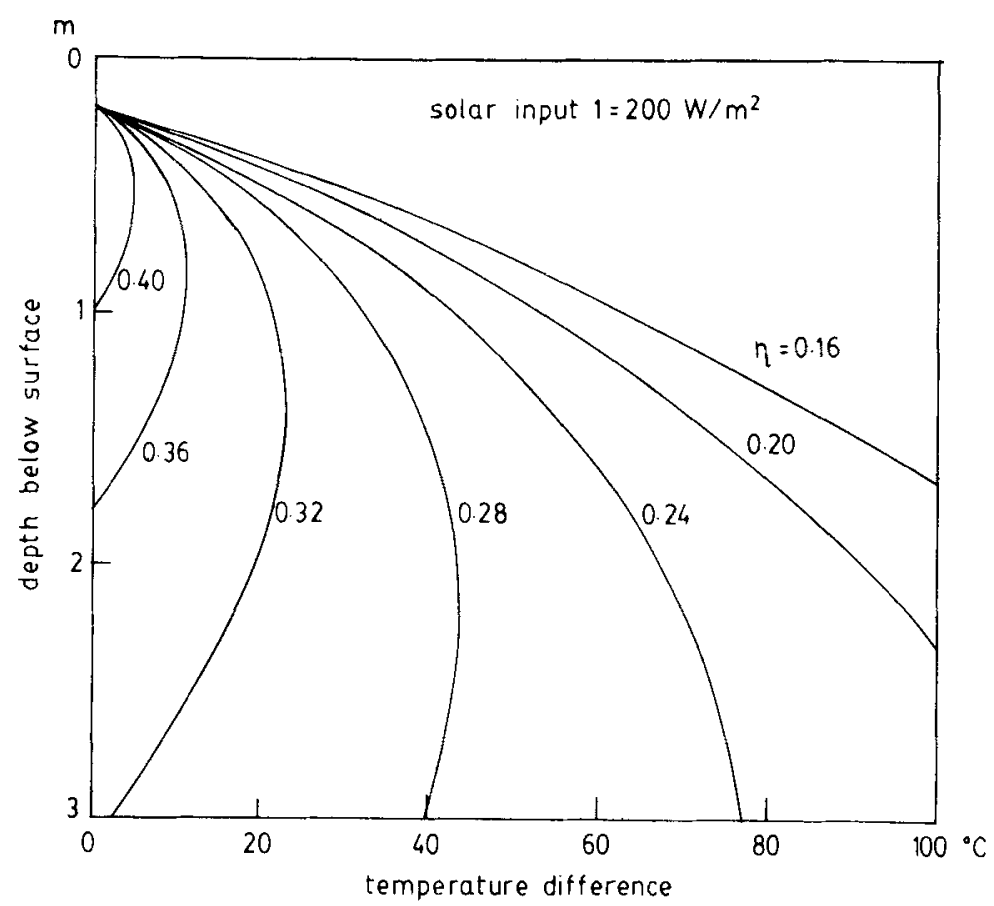

Figure 4. Variation of efficiency with depth and temperature difference.

can now be written as

$$
\eta=\frac{1}{Z_{2}-Z_{1}}\left[\int_{Z_{1}}^{Z_{2}} \tau(Z) \mathrm{d} Z-\frac{K_{w} \Delta T}{I}\right]-\frac{U_{g} \Delta T}{I},
$$

where $\Delta T$ is the temperature difference between the storage zone and the upper mixed layer.

Note that the optical efficiency of the solar pond is dependent upon the mean transmittance in the gradient zone. This is because the radiation absorbed in the gradient zone is helpful in reducing the heat losses from the storage zone.

The steady-state analysis of a solar pond is useful in the sizing of the pond for a specific application. There will, however, be strong seasonal variation in the performance of the pond on account of seasonal variations in solar insolation, wind and temperature. Srinivasan (1990) has proposed a simple two-zone model for the simulation of the storage zone temperature of the pond. How does this simple two-zone model predict the observed features of the seasonal variation of storage zone temperature in the Bangalore solar pond? The observed values of solar radiation, heat extraction and gradient zone thickness in the Bangalore solar pond were used in the simulation. The predictions of the storage zone temperature are compared with the observations (figure 5). The predicted storage zone temperatures are in good agreement with observation. Predictions based on climatological variation of solar radiation show higher deviation. This is because solar radiation in September 1986 was much lower than predicted by climatology. 


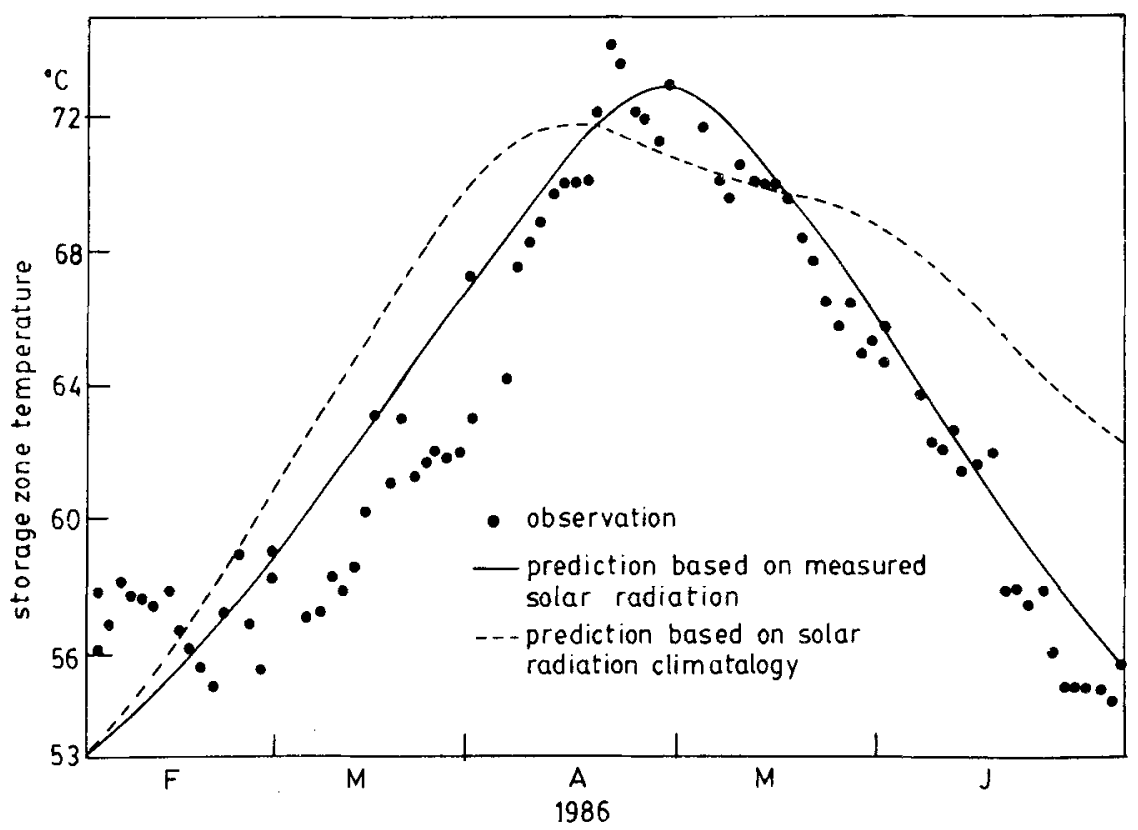

Figure 5. Variation of storage zone temperature with time in Bangalore solar pond.

\section{Pond construction}

The site selected for the construction of a solar pond should have the following attributes;

(a) be close to the point where thermal energy from the pond will be utilized;

(b) be close to a source of water for flushing the surface mixed-layer of the pond;

(c) the thermal conductivity of the soil should not be too high;

(d) the water table should not be too close to the surface.

An estimate of the area required for a solar pond (in the tropics) can be obtained from figure 6 (adapted from Fynn \& Short 1983). To minimize heat losses and liner costs, the pond should be circular. Since a circular pond is difficult to construct, a square pond is normally preferred. In some cases, such as the Bangalore solar pond, the site constraints may force one to construct a rectangular pond with large aspect ratio. For large solar ponds (area $>10,000 \mathrm{~m}^{2}$ ), the shape will not have a strong influence on cost or heat losses. The depth of the solar pond must be determined depending on the specific application. The usual thicknesses of the surface, gradient and storage zone of the pond are $0.5,1$ and $1 \mathrm{~m}$, respectively. If a particular site has low winds, one can reduce the thickness of the surface layer to $30 \mathrm{~cm}$. If the temperature required for process heat applications is around $40^{\circ} \mathrm{C}$ (such as hatcheries) then the thickness of the gradient zone can be reduced to $0.5 \mathrm{~m}$. Storage zone thickness higher than $1 \mathrm{~m}$ may be required to take care of long periods of cloudiness.

The excavation for a solar pond is similar to that for construction of water reservoirs. The side slope of the pond can vary between $1: 1$ to $1: 3$ depending upon the type of soil. After the excavation and bunding is completed, and before a liner is laid, one must ensure that the area is free of sharp objects which may damage the liner when it is being laid. 


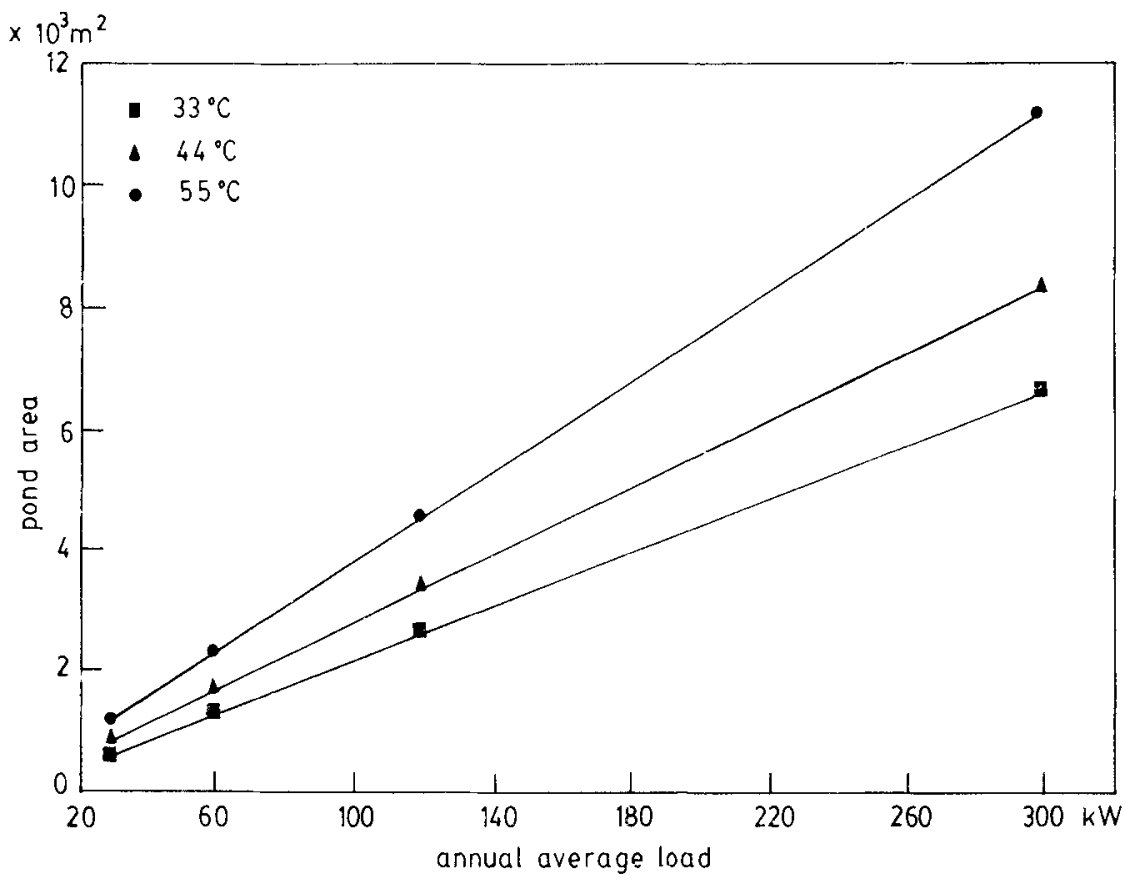

Figure 6. Solar pond area as a function of annual average pond load.

In most solar ponds, a polymeric liner is used to prevent the leakage of salt. Some solar ponds in Israel, Australia and Mexico have not been lined. This is because at those sites the soil has low permeability. Since the leakage of salt from a solar pond can cause environmental pollution it is necessary to use a liner in most applications. Many types of polymeric liner have been used in solar ponds. Some of them are low-density polyethylene (LDPE), high-density polyethylene (HDPE), plasticized polyvinyl chloride, chlorinated polyethylene (CPE), chloro-sulphonated polyethylene (Hypalon), ethylene propylene diene monomer (EPDM) and polymer-coated polyester fabric (XR-5). These liners are available usually in $10 \mathrm{~m}$ widths and hundreds of metres lengths, and are heat-sealed in the factory or in the field. Liners such as XR-5, EPDM and Hypalon can be used as exposed liners because they can resist ultraviolet degradation. Liners such as LDPE or HDPE undergo ultraviolet degradation and, hence, need to be covered with soil, brickwork or tiles. In the Bangalore solar pond three LDPE liners have been used. The topmost liner was used as sacrificial liner and replaced every two years. After the installation of the liner it can be tested for leaks by using a portable blower. If there are any pin holes or leakages at joints the liner will billow upwards. An inexpensive method to reduce leakage from pin holes is the use of Bentonite clay between adjacent LDPE liners. When Bentonite clay absorbs moisture it swells considerably and blocks further leakage. The use of alternate layers of LDPE and clay has been implemented at the $210,000 \mathrm{~m}^{2}$ solar pond at Bet $\mathrm{Ha}$ Arava in Israel. After the installation of the liner, it is useful to have a method for detection of any leakage of salt. Hull et al (1989) have shown that an accurate calculation of salt inventory in the pond will provide indication of leak as low as $1 \mathrm{~mm}$ per month.

After the liner is placed, the pond is filled with water to a depth equal to the thickness of the storage zone and half the gradient zone. Salt is directly dumped into 


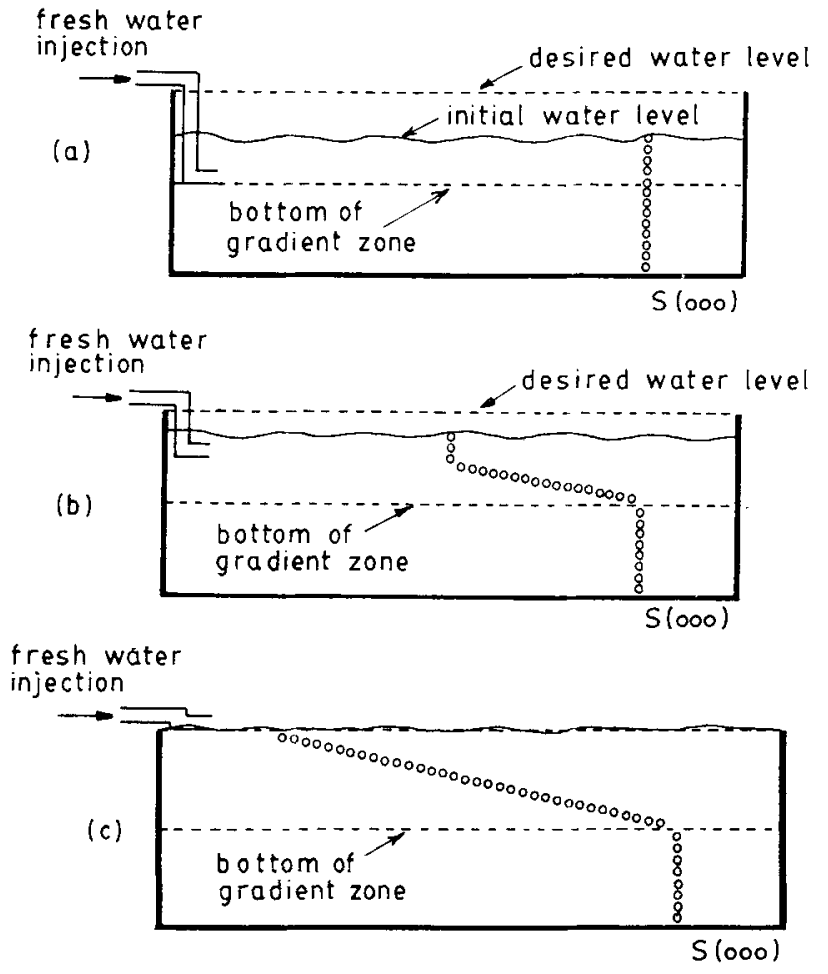

Figure 7. Establishment of initial (a), halfway (b) and final (c) gradient zones in a solar pond. (From Hull et al 1989.)

the pond. The salt dissolves rapidly if the water in the pond is circulated through a pump and the water is directed as a jet into the pond. The concentration of the salt at the storage zone is between 200 to $300 \mathrm{~kg} / \mathrm{m}^{3}$. Hence the salt inventory is between $1 / \hat{\jmath}$ to $1 / 2$ ton per $\mathrm{m}^{2}$. The normal method of establishing the gradient zone is by injection of fresh water. This method, developed by Zangrando (1980), is convenient and hence has been adopted in most solar pond installations in the world. Fresh water injection is initiated at the interface between the storage zone and the gradient zone using a diffuser (see figure 7). The fresh water rises to the top and reduces the density of the layer above the injection point. For every $1 \mathrm{~cm}$ rise in water level, the diffuser is lifted by $2 \mathrm{~cm}$. When the diffuser is at the same level as the water surface the establishment of the gradient zone is completed. More fresh water is added above the gradient zone to create an upper mixed layer with a thickness of 30 to $50 \mathrm{~cm}$. The evolution of density profile during the establishment of the gradient zone in the Miamisburg solar pond is shown in figure 8.

After the establishment of the gradient zone, the pond begins to heat up if clear sky conditions prevail. The temperature in the storage zone of the Bangalore solar pond increased by $30^{\circ} \mathrm{C}$ within one month of the establishment of the gradient zone.

\subsection{Pond stability}

A solar pond will be statically stable if its density decreases with height from the bottom. A solar pond is subjected to various disturbances such as the wind blowing at the top surface and heating of the side walls. The criterion for dynamic stability of the pond is somewhat more stringent than that for static stability. This criterion can be obtained by perturbation analysis of the basic laws of conservation of mass, 


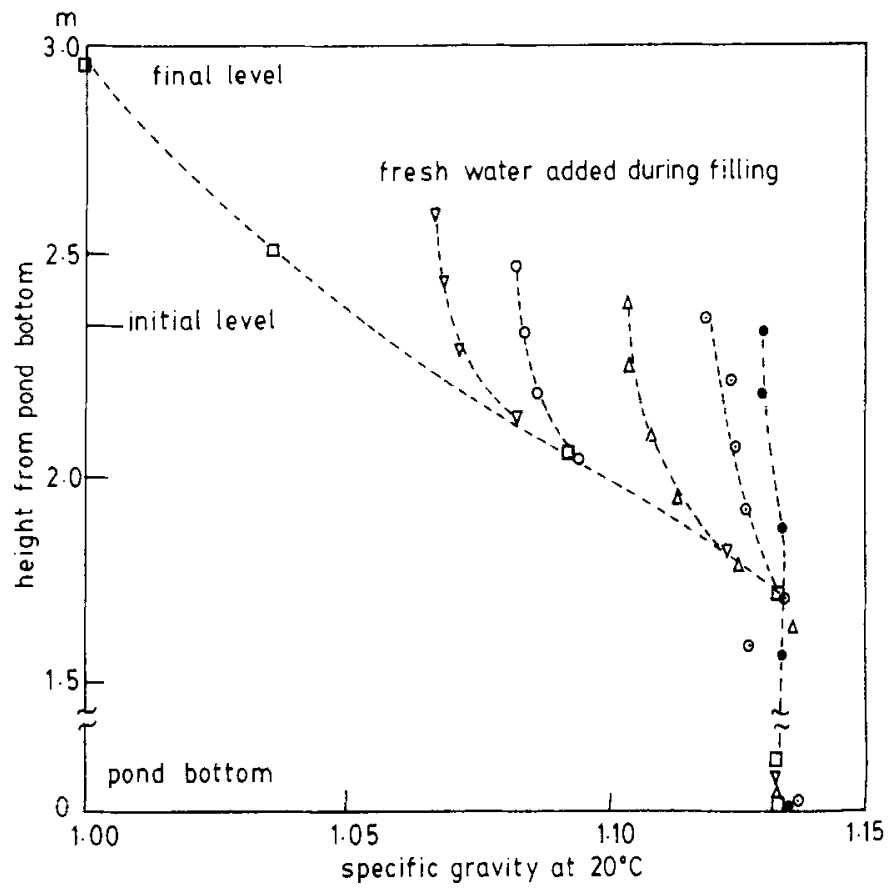

Figure 8. Evolution of gradient zone during establishment in the Miamisburg solar pond.

momentum and energy. This has been discussed in great detail by Nield (1967) and Baines \& Gill (1969). The criterion for stability obtained from such an analysis can be written as

where

$$
\beta_{T} \frac{\partial T}{\partial Z}<\beta_{S} \frac{\partial S}{\partial Z}\left[\frac{\mathrm{Sc}+1}{\operatorname{Pr}+1}\right]
$$

$$
\begin{aligned}
& \beta_{T}=-\frac{1}{\rho}\left[\frac{\partial \rho}{\partial T}\right]=\text { thermal expansion coefficient } \\
& \beta_{S}=+\frac{1}{\rho}\left[\frac{\partial \rho}{\partial S}\right]=\text { salinity expansion coefficient } \\
& \mathrm{Pr}=\text { Prandtl number, } \\
& \mathrm{Sc}=\text { Schmidt number. }
\end{aligned}
$$

For typical conditions encountered in a solar pond, this result can be simplified to

$$
\frac{\partial S}{\partial Z}>1 \cdot 19 \frac{\partial T}{\partial Z}
$$

where $S$ is in $\mathrm{kg} / \mathrm{m}^{3}$ and $T$ in ${ }^{\circ} \mathrm{C}$.

In order to prevent formation of internal convective zones within the gradient zone it is essential that the above criterion is satisfied at all points within the gradient zone. Hull et al (1989) have recommended that a safety margin of 2 is desirable. 
Safety margin (SM) is defined as

where

$$
\mathrm{SM}=\left(\frac{\partial S}{\partial Z}\right)_{\text {actual }} /\left(\frac{\partial S}{\partial Z}\right)_{\text {theoretical }},
$$

$$
\left(\frac{\partial S}{\partial Z}\right)_{\text {theoretical }}=\frac{\beta_{T}}{\beta_{S}}\left[\frac{\operatorname{Pr}+1}{\mathrm{Sc}+1}\right] \frac{\partial T}{\partial Z} .
$$

In the Bangalore solar pond, an internal convective zone was formed although the safety margin was above 2 (figure 9). This is believed to be on account of side wall heating. Akbarzadeh (1984) has performed laboratory experiments to study the effect of side-wall heating on the formation of internal convective zones. These studies indicate that side-wall heating can result in the formation of internal convective zones. In the Bangalore solar pond, the distance between the side walls was as low as $9 \mathrm{~m}$ at the bottom of the gradient zone. The free convective boundary layers that formed on the side walls could have merged at the centre and led to the formation of internal convective zones. In large solar ponds, side-wall heating would not be able to initiate the formation of internal convective zones and hence a safety margin around 2 should be adequate.

The thickness of the gradient zone (which provides insulation and hence reduces heat losses) can be reduced by the formation of internal convective zones or erosion of the boundaries of the gradient zone. Erosion of the gradient zone-surface zone interface occurs primarily on account of wind-induced mixing. The effect of windinduced mixing can be reduced by using floating plastic nets or pipes. Nielsen (1983) has reported that mean-squared wind speeds exceeding $20 \mathrm{~m}^{2} / \mathrm{s}^{2}$ caused the erosion of the gradient zone at the rate of $1 \mathrm{~cm} /$ day, while for values below $10 \mathrm{~m}^{2} / \mathrm{s}^{2}$ there was no gradient erosion.
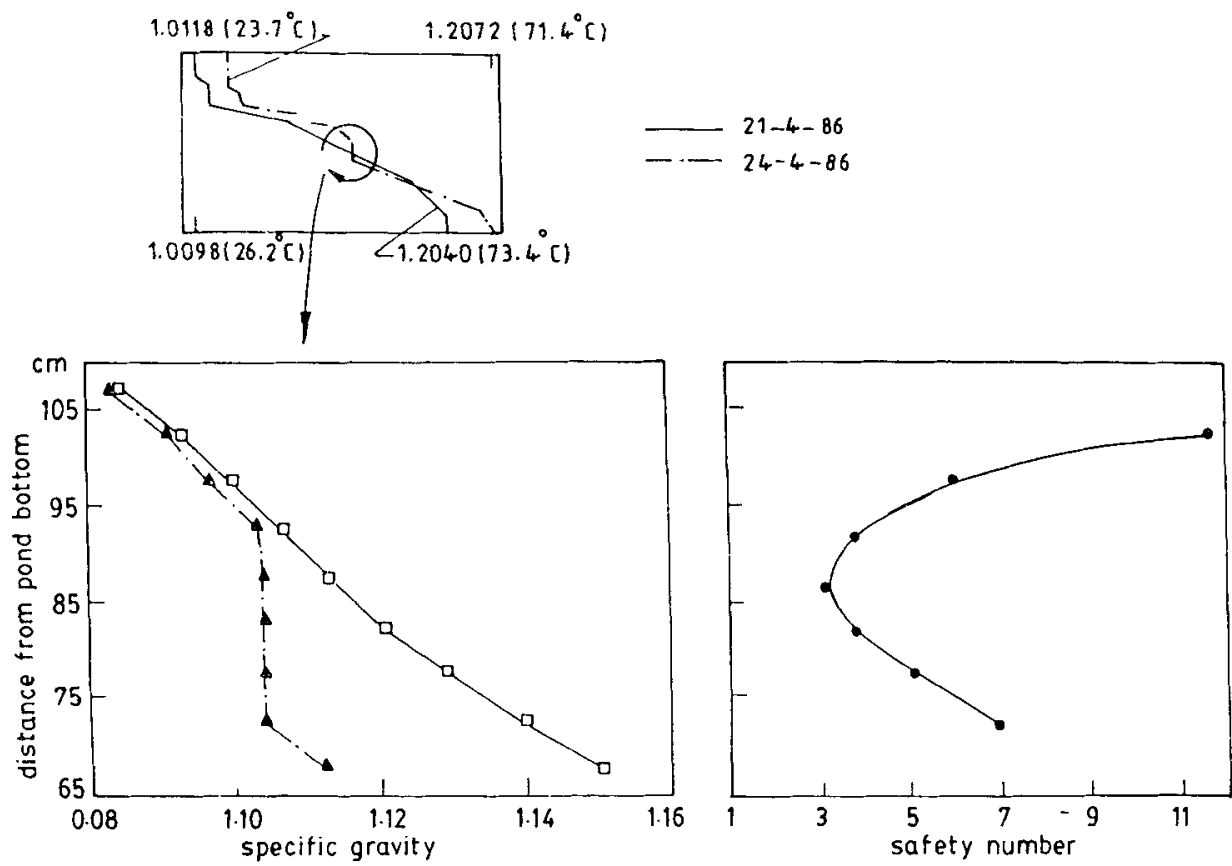

Figure 9. Formation of internal convective zone in the Bangalore solar pond. 
Erosion of the gradient zone from below depends upon the density and temperature gradients at the gradient zone-storage zone interface. Nielsen (1983) has determined experimentally that the gradient zone-storage zone interface remains stationary if the salinity and temperature gradients satisfy the following relationship.

where

$$
\partial S / \partial Z=A[\partial T / \partial Z]^{0 \cdot 63}
$$

$$
A=28\left(\mathrm{~kg} / \mathrm{m}^{4}\right)(\mathrm{m} / \mathrm{K})^{0.63} \text {. }
$$

If the actual salinity gradient is more than that given by the above criterion, the gradient zone will move downwards, while if it is less, the gradient zone will erode.

To ensure that the gradient zone does not erode from above, the density of the surface layer must be kept as low as possible. The density of the surface layer increases on account of diffusion of salt from below and because of evaporation. Hence the surface layer must be flushed regularly with fresh water to keep the salinity below $5 \%$ (by weight).

\subsection{Salt replenishment}

On account of the gradient of concentration between the storage and the surface zones, there is a steady diffusion of salt through the gradient zone. The transport of salt through the gradient zone by diffusion can be expressed as

$$
Q_{m}=\left[\left(S_{l}-S_{u}\right) D\right] / b,
$$

where $b=$ thickness of gradient zone, $D=$ mass diffusion coefficient, and $S_{l}, S_{u}=$ salinity in lower and upper mixed layers, respectively.

If the salinity in the storage zone is $300 \mathrm{~kg} / \mathrm{m}^{3}$ and in the surface zone is $20 \mathrm{~kg} / \mathrm{m}^{3}$, gradient zone thickness is $1 \mathrm{~m}$ and diffusion coefficient of salt is $3 \times 10^{-9} \mathrm{~m}^{2} / \mathrm{s}$, then the rate of transport of salt by diffusion will be about $30 \mathrm{~kg} / \mathrm{m}^{2}$ year. In small solar ponds the salt transport can be as high as $60 \mathrm{~kg} / \mathrm{m}^{2}$ year because of additional salt transport through side-wall heating.

If the salt lost from the storage zone is not replenished regularly then there may be an erosion of the gradient zone from below or formation of internal convective zones. The normal method of salt replenishment is by pumping the brine in the storage zone through a salt bed (figure 10); Srinivasan (1990) has shown that for small solar ponds a passive salt replenishment technique is adequate (figure 11). In the Bangalore solar pond $\left(240 \mathrm{~m}^{2}\right.$ bottom area) about $100 \mathrm{~kg}$ of salt was added daily through a chute into the storage zone. The salt that was added dissolved within a day.

\subsection{Algae control}

The thermal efficiency of a solar pond is strongly dependent upon the clarity of the pond, which is reduced by the presence of algae or dust. Bits of debris/dust or leaves lighter than water float on the surface and can be skimmed off. Dust and debris much heavier than water will sink to the bottom. Srinivasan \& Guha (1987) have reported that the dust accumulating at the bottom of the pond does not adversely affect the absorption of solar radiation at the bottom of the pond. The dust floating in the gradient zone can be settled by adding alum. The growth of algae can be controlled by adding bleaching powder or copper sulphate. If the water used in the pond is alkaline, copper sulphate will not dissolve. Hull (1990) has provided a detailed account of the relative merits of various methods of algae control. 


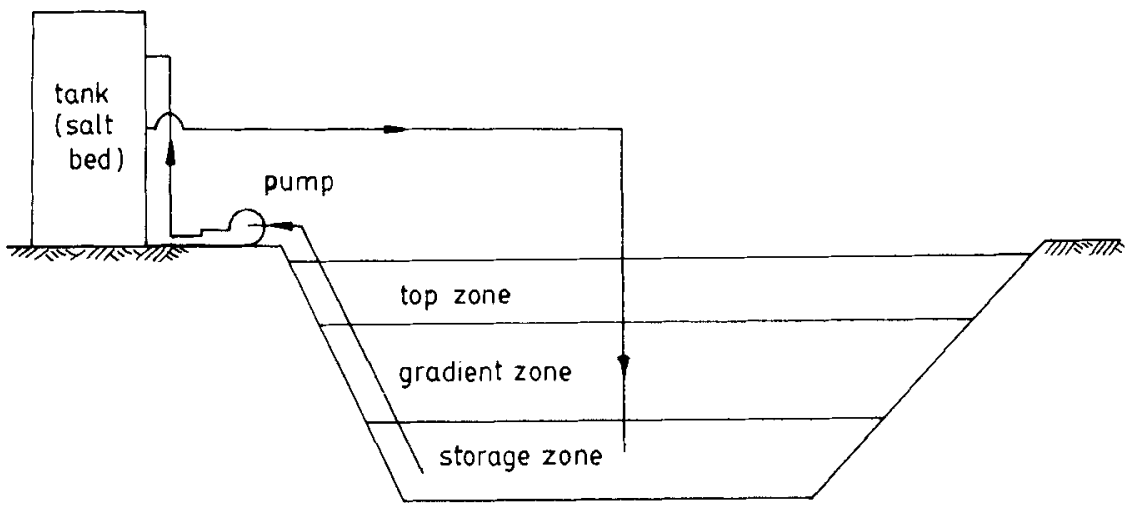

Figure 10. Salt replenishment in solar pond through an external salt bed (active replenishment).

\subsection{Heat extraction}

Heat can be extracted from the pond using an internal or an external heat exchanger. The internal heat exchanger is immersed in the storage zone. Such heat exchangers are made of copper or plastic to eliminate the effect of corrosion, and are appropriate for small solar ponds. In large solar ponds (area $>1000 \mathrm{~m}^{2}$ ) external heat exchangers may be more convenient. These are made of stainless steel or titanium. In the Bangalore solar pond experiments were conducted with three heat exchangers: (1) a titanium heat exchanger (external), (2) a copper heat exchanger (immersed) and (3) a plastic heat exchanger (immersed). The immersed copper heat exchanger was found to be most reliable in the Bangalore solar pond. Hull et al (1985) have demonstrated that a polypropylene submerged heat exchanger can be used in a solar pond although its effectiveness will not be as high as a copper heat exchanger.

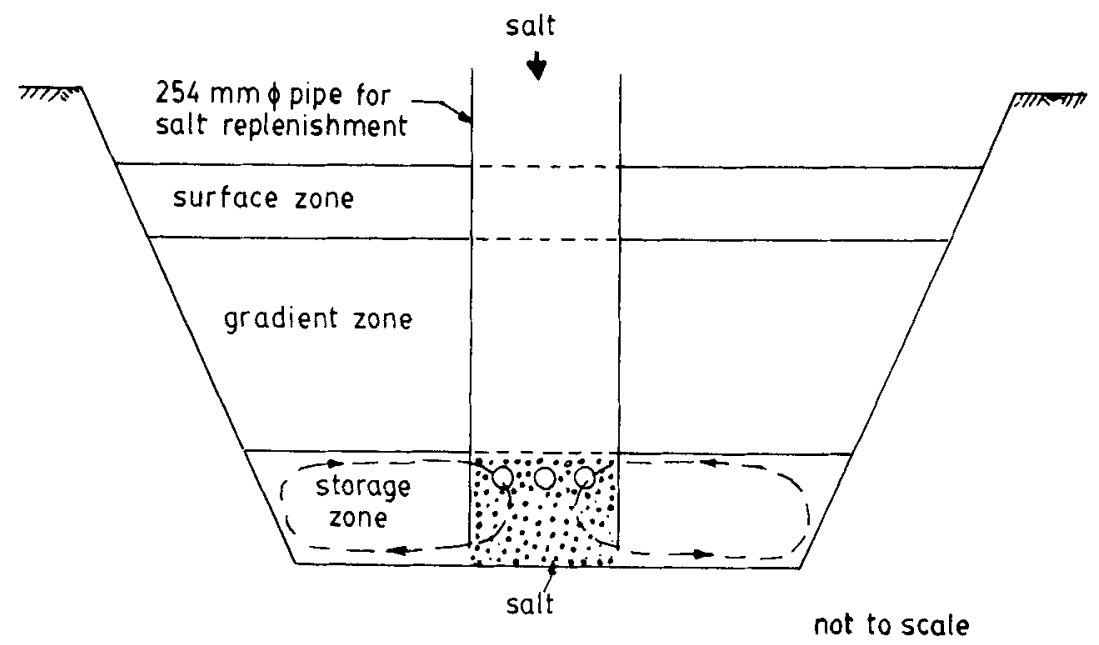

Figure 11. Passive salt replenishment. 


\subsection{The effect of rainfall}

Rainfall can have beneficial as well as detrimental effects on the operation of a solar pond. If the rainfall is not heavy, it helps to maintain the density of the surface layer at a low value. During the monsoon, in the Bangalore solar pond, there was no need for flushing the surface layer to maintain its density at a low value. Heavy monsoon rainfall can, however, penetrate to the gradient zone and dilute it. The analysis of heavy rainfall (greater than $40 \mathrm{~mm}$ per hour) episodes in the Bangalore solar pond indicates that raindrops can penetrate to about $50 \mathrm{~cm}$ from the surface. Hence, it may be desirable to maintain higher surface zone thickness during the rainy season.

\section{Solar pond applications}

In the last thirty years more than sixty solar ponds have been built all around the world. The largest solar pond built so far is the $250,000 \mathrm{~m}^{2}$ pond at Bet $\mathrm{Ha}$ Arava in Israel. This pond has been used to generate $5 \mathrm{MWe}$ (peak) power using an organic Rankine cycle. The heat stored in the solar pond can be used in a variety of applications.

In Argentina, solar ponds are being used commercially for production of sodium sulphate using solution-refining techniques. The ore (rich in sodium sulphate) mined in the Andes Mountains is dissolved in a $400 \mathrm{~m}^{2}$ solar pond constructed adjacent to the mines. The brine is removed and placed in a cooling pond at night where sodium sulphate crystallizes (for details, see Lesino et al 1982). Solar pond concepts have been used to prevent precipitation of magnesium sulphate in the salt works at the Great Salt Lake in Utah, USA.

A $2000 \mathrm{~m}^{2}$ solar pond has been constructed to provide hot water for a swimming pool in Miamisburg, Ohio, USA. A $3355 \mathrm{~m}^{2}$ solar pond at El Paso, Texas, has demonstrated the use of a solar pond for food processing, power generation and desalination. The feasibility of grain drying using a solar pond has been demonstrated at Montreal (Canada), Ohio (USA) and for heating greenhouses at Lisbon (Portugal). A $20,000 \mathrm{~m}^{2}$ solar pond in Italy has been used for desalination of sea water and producing 120 tonnes of fresh water per day.

The major limitation of solar ponds for industrial applications is the fact that the temperature in the storage layer cannot go beyond $95^{\circ} \mathrm{C}$. Many industries require process temperatures above $100^{\circ} \mathrm{C}$. Gommed \& Grossman (1988) have discussed the use of an absorption heat pump in conjunction with a solar pond to generate steam. If this approach is successful, it will open up new applications for thermal energy from solar ponds.

\subsection{The Indian experience}

The first solar pond in India was a $1200 \mathrm{~m}^{2}$ pond built at the Central Salt and Marine Chemicals Research Institute in Bhavnagar, Gujarat, in 1970. This solar pond was based on bittern, which is a waste product during the production of sodium chloride from sea water. The second solar pond was a $100 \mathrm{~m}^{2}$ circular pond built in Pondicherry in 1980. This pond used sodium chloride and was operational for two years. Patel \& Gupta (1981) have discussed the performance of this pond. The LDPE liner used in this pond developed a leak and hence had to be replaced. Patel \& Gupta (1981) have shown that a new liner could be placed in the pond without too much loss of thermal 
energy. The third solar pond was a $1600 \mathrm{~m}^{2}$ solar pond built at Bhavnagar in 1980 . This pond was based on bittern and hence had problems with the clarity of bittern. The fourth solar pond was a $240 \mathrm{~m}^{2}$ solar pond commissioned at the Indian Institute of Science, Bangalore, in 1984. This pond has provided long-term data on continuous heat extraction from small solar ponds and has demonstrated the technical and economic viability of small solar ponds for low temperature process heat. Srinivasan (1985) has argued that low temperature process heat from small solar ponds can be used in hatcheries, hostels and dairies. A $400 \mathrm{~m}^{2}$ solar pond has been constructed at Masur on the West Coast of India to supply hot water needs of a rural community. A $300 \mathrm{~m}^{2}$ solar pond is being built for an engineering college at Hubli (Karnataka) to supply hot water for student hostels. A $6000 \mathrm{~m}^{2}$ solar pond has been completed in Bhuj (Gujarat) and is expected to supply hot water for a dairy. This project is expected to explore the potential for desalination and power generation. $\mathrm{A} 6000 \mathrm{~m}^{2}$ solar pond is under construction at Pondicherry for generation of $100 \mathrm{kWe}$ (peak) power. The solar ponds at Masur and Bhuj experienced salt leakages on account of the failure of LDPE liners.

In India, Gujarat and Tamil Nadu are the two states where common salt is produced on a large-scale. These two states have arid regions where the land is unsuitable for agriculture and have more than 300 clear days a year. Gujarat and Tamil Nadu constitute $10 \%$ of India's area. If $4 \%$ of the land in these two states were used as solar pond power plants, they can generate about 200 billion kilowatt hours of electrical energy. Thus, solar pond power plants could have met all the electrical energy needs of India in 1988. Solar ponds should therefore play an important role in meeting the future energy needs of India using a locally available and renewable energy source.

\subsection{Economics}

Solar energy conversion devices have not found widespread application because they require high initial capital investment. The cost of a solar pond is much less than that of the conventional flat plate collectors. The cost of a solar pond is, however, strongly dependent upon site-specific factors such as the local cost of excavation and salt. The thermal performance of a solar pond is also dependent on site-specific factors such as solar irradiation, ground thermal conductivity and water-table depth. Hence, there is bound to be large variation in the cost of thermal energy produced by solar ponds at different sites.

Rao \& Kishore (1989) and Hull et al (1989) have provided a detailed analysis of the various components of the cost of a solar pond. If the cost of salt and its recycling is excluded, Hull et al (1989) estimate the cost of a large solar pond (area $>100,000 \mathrm{~m}^{2}$ ) to be around US $\$ 10 / \mathrm{m}^{2}$ (in 1986) and that of a small solar pond (area around $1000 \mathrm{~m}^{2}$ ) to be around US $\$ 50 / \mathrm{m}^{2}$. If the cost of salt is $\$ 40 /$ tonne the cost of large and small solar ponds are around $\$ 45 / \mathrm{m}^{2}$ and $\$ 85 / \mathrm{m}^{2}$, respectively. In the estimates provided by Hull et al (1989), the cost of salt represents $50 \%$ of the total cost of a small solar pond and more than $75 \%$ of the total cost of a large solar pond. Hence, it is essential that large solar ponds be located close to sites where salt is available at low cost. In India, small solar ponds can be constructed at a cost of Rs 200 to Rs 400 per $\mathrm{m}^{2}$ (Srinivasan 1985; Rao \& Kishore 1989). Rao \& Kishore (1989) have provided the following detailed breakdown of the cost of a solar pond per square 
metre $C_{p}$.

$$
\begin{aligned}
C_{p}= & 2.546\left(C_{1}+C_{2}\right)+0.675 C_{3}+1.3 C_{4}+0.456 C_{5}+0.0415 C_{6} \\
& +0.124 C_{7}+0.021 C_{8}+0.085 C_{9}+C_{10},
\end{aligned}
$$

where $C_{1}=$ excavation charges, $\mathrm{Rs} / \mathrm{m}^{3} ; C_{2}=$ water charges, $\mathrm{Rs} / \mathrm{m}^{3} ; C_{3}=$ salt cost, Rs/tonne; $C_{4}=$ liner cost, Rs $/ \mathrm{m}^{2} ; C_{5}=$ clay, Rs/tonne; $C_{6}=$ cost of bricks, Rs $/ 1000$ bricks; $C_{7}=$ cost of cement, Rs $/$ bag; $C_{8}=$ cost of sand, Rs $/ \mathrm{m}^{3} ; C_{9}=$ cost of brick lining, $\mathrm{Rs} / \mathrm{m}^{3} ; \mathrm{C}_{10}=$ cost of wave suppresser, Rs $/ \mathrm{m}^{2}$.

Rao \& Kishore (1989) have used the net present-value method to estimate the cost of thermal or electrical energy from solar ponds. The cost of thermal energy from solar ponds can be estimated as

$$
C_{\mathrm{th}}=\left[\mathrm{CRF} \times C_{p}+C_{M}\right] / \eta_{p} S_{i},
$$

where $C_{\mathrm{th}}=$ cost of thermal energy, Rs $/ \mathrm{kWh} ; C_{p}=$ capital cost of the solar pond, $\mathrm{Rs} / \mathrm{m}^{2} ; C_{M}=$ maintenance cost of solar pond, Rs $/ \mathrm{m}^{2} ; \eta_{p}=$ thermal efficiency of solar pond, $S_{i}=$ average incident solar energy, $\mathrm{kWh} / \mathrm{m}^{2}$ year.

The variation of the cost of thermal energy from the pond for various values of the capital cost of the pond and the maintenance cost of the pond is shown in figure 12 . We find that solar ponds produce thermal energy at a cost lower than that obtained from burning fossil fuels or electricity.

Rao \& Kishore (1989) have estimated the cost of electricity obtained from a solar pond as follows

$$
C_{E}=\frac{C_{R}\left[C_{p}+C_{p p} G_{e} / N\right]+C_{M}}{G_{e}(1-f)},
$$

where $C_{E}=$ cost of electricity, Rs/kWhe; $C_{R}=$ capital recovery factor; $C_{p}=$ cost of

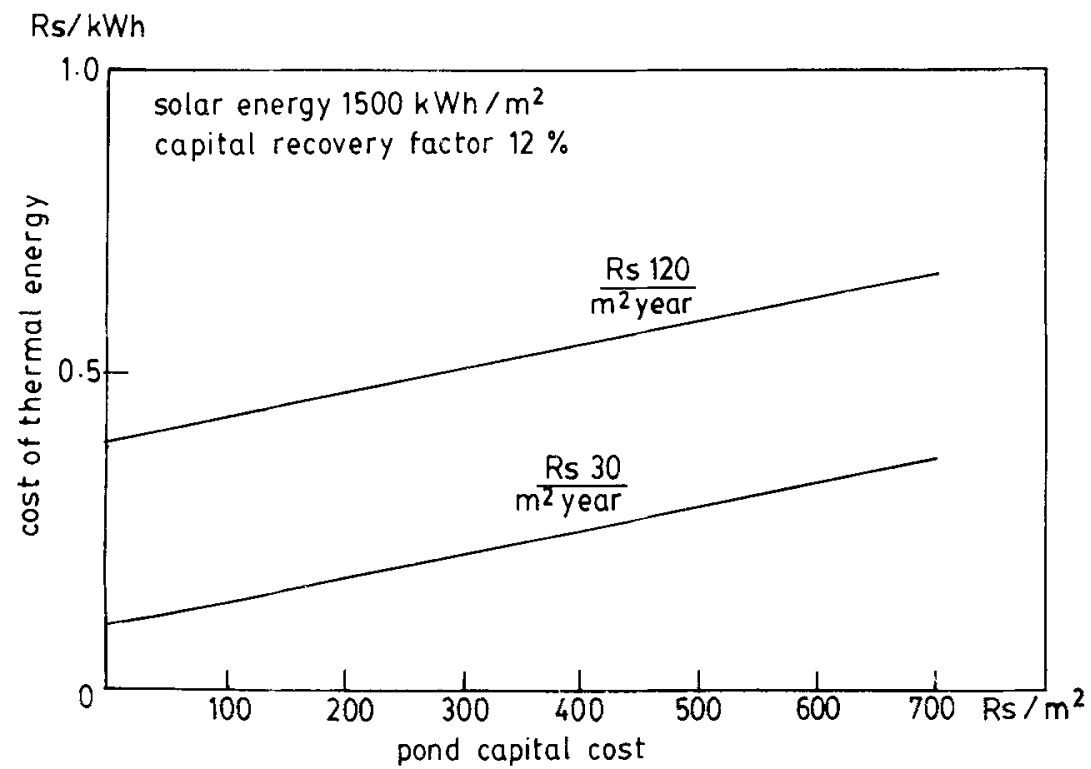

Figure 12. Cost of thermal energy as a function of pond capital cost. 
solar pond, Rs $/ \mathrm{m}^{2} ; C_{p p}=$ cost of organic Rankine cycle power plant, Rs per $\mathrm{kWe}$; $G_{e}=$ gross electricity generation, $\mathrm{kWhe} / \mathrm{m}^{2} ; N=$ number of hours of operation per year; $C_{M}=$ maintenance cost, Rs $/ \mathrm{m}^{2} ; f=$ fractional parasitic losses.

If we assume that $C_{R}=0.125, C_{P}=\mathrm{Rs} 140 / \mathrm{m}^{2}, G_{e}=20 \mathrm{kWhe} / \mathrm{m}^{2}, C_{p p}=\mathrm{Rs}$ $1500 / \mathrm{kWe}, N=5000 \mathrm{~h}, C_{M}=\mathrm{Rs} 7 / \mathrm{m}^{2}$, and $f=0.2$, we obtain $C_{E}=\mathrm{Rs} 2 / \mathrm{kWhe}$. We find that the cost of electricity obtained from a solar-pond power plant is higher than that obtained from fossil fuel-based thermal power plants but is comparable to the cost of electricity from diesel generation sets. From the above analysis we can also infer that the cost of electricity from a solar-pond power plant will reduce to Rs $1 / \mathrm{kWhe}$ if the capital cost of the solar pond reduces to $\mathrm{Rs} 12 / \mathrm{m}^{2}$. This is impossible to achieve unless there is a natural site (such as a salt lake) which requires no salt, digging, or liner. We can conclude, therefore, that electricity generation from solar ponds is not economically viable unless the site conditions are extremely favourable.

\section{Conclusions}

Solar pond technology has made tremendous progress in the last fifteen years. An excellent monograph is now available on the science and technology of salinity gradient solar ponds (Hull et al 1989). This technology is cost effective for low temperature process heat needs of industry. The generation of electricity using solar ponds is not economically viable as yet. However, the new concerns regarding the environment and the safety of nuclear power plants and nuclear waste disposal may change the picture totally.

\section{References}

Akbarzadeh A 1984 A further study on the effect of sloping walls and the included instabilities on the operation of solar ponds. Proceedings Australia and New Zealand Sec., International Solar Energy Society, Auckland, New Zealand, 212-S2/44-AA

Baines P G, Gill A E 1969 On thermohaline convection with linear gradients. J. Fluid Mech. 37: 289-306

Fynn R P, Short T H 1983 Solar ponds. Special Circular 106, The Ohio State University, Ohio Agricultural Research and Development Centre, Wooster, Ohio, February 1983

Gommed K, Grossman G 1988 Process steam generation by temperature boosting of heat from solar ponds. Sol. Energy 41: 81-89

Hull J R 1990 Maintenance of brine transparency in salinity gradient solar ponds. J. Sol. Energy Eng. 112: 65-69

Hull J R, Liu K V, Sha W T, Kamal J, Nielsen C E 1984 Dependence of groundheat loss upon solar pond size and perimeter insulation; calculated and experimental results. Sol. Energy 33: 25-33

Hull J R, Nielsen C E, Golding P 1989 Salinity gradient solar ponds (Boca Raton, FL:CRC Press)

Hull J R, Scranton A B, Kasze K E 1985 Solar pond heat removal using a submerged heat exchanger. Proceedings, International Solar Energy Society (Montreal) (New York: Pergamon) p. 1505

Kooi C F 1979 The steady state salt gradient solar pond. Sol. Energy 33: 37-45

Lesino G, Saravia L, Mangussi J, Caso R 1982 Operation of a $400 \mathrm{~m}^{2}$ sodium sulfate solar pond in Saita, Argentina. Int. Solar Pond Lett. 1: 12

Nield D A 1967 The thermohaline Rayleigh-Jaffreys problem. J. Fluid Mech. 29: 545-558

Nielsen C E 1980 Nonconvective salt-gradient solar ponds. In Solar energy technology handbook (eds) W C Dickinson, P N Cheremisinoff (New York: Marcel Dekker) 
Nielsen C E 1983 Experience with heat extraction and zone boundary motion. Proceedings American Solar Energy Society (Minneapolis) p. 405

Ortabasi U, Dyksterhuis F 1985 Experience with honeycomb stabilized solar ponds for heat and power generation. Proceedings, International Solar Energy Society (Montreal) (New York: Pergamon) p. 1485-88

Patel S M, Gupta C L 1981 Experimental solar pond in a hot humid climate. Sunworld 5: $115-118$

Rao K S, Kishore V V N 1989 Power generation from solar ponds. In Techno-economics of renewable energy power generation system (eds) K S Rao, V V N Kishore, N K Bansal (New Delhi: Sarita)

Rabl A, Nielsen C E 1975 Solar ponds for space heating. Sol. Energy 17: 1-12

Srinivasan J 1985 Construction and performance of an experimental solar pond. KSCST report $85 \mathrm{SP} 1$

Srinivasan J 1990 Performance of a small solar pond in the tropics. Sol. Energy 45: 221-230

Srinivasan J, Guha A 1987 The effect of bottom reflecting on the performance of a solar pond. Sol. Energy 39: 361-367

Wilkins E S, Lee T K 1987 Development of the gel pond technology. Sol. Energy 39: 33-51

Zangrando F 1980 A simple method to establish salt gradient solar ponds. Sol. Energy 25: $467-470$ 